Check for updates

Cite this: RSC Adv., 2018, 8, 34877

Received 28th August 2018

Accepted 4th October 2018

DOI: $10.1039 / \mathrm{c} 8 \mathrm{ra} 07167 \mathrm{e}$

rsc.li/rsc-advances

\title{
Convenient and sensitive colorimetric detection of melamine in dairy products based on $\mathrm{Cu}(\mathrm{II})-\mathrm{H}_{2} \mathrm{O}_{2}-$ 3,3',5,5'-tetramethylbenzidine system $\dagger$
}

\author{
Xue Han, Zhixin Qin, Mengyao Zhao, Jiajia Song, Fei Qu, (D) Fengli Qu (D) \\ and Rong-Mei Kong (DD *
}

\begin{abstract}
The illegal adulteration of melamine in dairy products for false protein content increase is a strong hazard to human health. Herein, a simple and sensitive colorimetric method was developed for the quantification of melamine in dairy products based on a $\mathrm{Cu}^{2+}$-hydrogen peroxide $\left(\mathrm{H}_{2} \mathrm{O}_{2}\right)-3,3^{\prime}, 5,5^{\prime}$ tetramethylbenzidine (TMB) system. In this strategy, $\mathrm{Cu}^{2+}$ exhibits peroxidase-like activity and can catalyze the oxidation of TMB to oxidized TMB (oxTMB) in the presence of $\mathrm{H}_{2} \mathrm{O}_{2}$ with a blue colour change of the solution. However, the presence of melamine quickly interacts with $\mathrm{H}_{2} \mathrm{O}_{2}$ leading to the consumption of $\mathrm{H}_{2} \mathrm{O}_{2}$ and thus strongly hinders the oxidation of TMB. Under the optimal conditions, the absorbance change of oxTMB has a linear response to the concentration of melamine from 1 to $100 \mu \mathrm{M}$ with a detection limit of $0.5 \mu \mathrm{M}$ for melamine. The proposed method has many merits including more simplicity, good selectivity, and more cost-effectiveness without using any nanomaterials. The method was further successfully applied to detect melamine in dairy products including milk and infant formula powder.
\end{abstract}

\section{Introduction}

Melamine $\left(\mathrm{C}_{3} \mathrm{H}_{6} \mathrm{~N}_{6}\right)$, as a well-known industrial chemical product has been widely used in the synthesis of melamine formaldehyde resins for manufacturing laminates, plastics, commercial filters, dishware and so on. ${ }^{1}$ Since the classical Kjeldahl protein analysis method cannot avoid the interference of nonprotein nitrogen (NPN) reagent, melamine has been used to illegally adulterate dairy products for the purpose of inflating the apparent protein level due to its high nitrogen content $(66 \%)^{2,3}$ However, the consumption of dairy products contaminated with melamine can lead to urinary system damage, urinary calculi, acute renal failure, bladder cancer, and even infant death, ${ }^{4}$ because of the precipitation of insoluble melamine cyanurate through a reaction of melamine and its hydrolyzate cyanuric acid. ${ }^{5}$ Considering its adverse effects, the U.S. Food and Drug Administration (FDA) strictly stipulated the limit dosage of melamine which is $1 \mathrm{ppm}(8.0 \mu \mathrm{M})$ for infant milk and $2.5 \mathrm{ppm}(20 \mu \mathrm{M})$ for other dairy products. ${ }^{6,7}$ Therefore, it is highly desirable to develop facile and reliable methods for the quantificational detection of melamine in dairy products.

Up to now, some efficient and selective detection methods have been implemented to detect melamine such as high

College of Chemistry and Chemical Engineering, Qufu Normal University, Qufu, Shandong 273165, P. R. China. E-mail: kongrongmei@126.com

$\dagger$ Electronic supplementary information (ESI) available. See DOI: 10.1039/c8ra07167e performance liquid chromatography (HPLC), ${ }^{8}$ gas chromatography/mass spectroscopy (GC/MS), ${ }^{9}$ liquid chromatography/mass spectrometry (LC/MS), ${ }^{10}$ capillary electrophoresis (CE), ${ }^{11}$ surface-enhanced Raman scattering (SERS), ${ }^{12,13}$ and enzyme-linked immune sorbent assay (ELISA). ${ }^{14}$ However, these traditional instrumental analysis measurements always require expensive instruments and complicated sample preparation, which greatly limit their applications for routine melamine detection. In recent years, the determination of melamine based on electrochemical, ${ }^{3,15,16}$ fluorescent ${ }^{17-23}$ and colorimetric assays ${ }^{24-29}$ have attracted increasing attention from researchers. Although many of the above methods were wellestablished without a complicated pretreatment process and instrumentation during the assay operations, the disadvantages such as time-consuming, sophisticated experimental design and operation involved may also limit their practical applications. Particularly with the development of nanoscience and nanotechnology, various kinds of nanomaterials have been applied for the determination of melamine due to their unique properties such as fluorescence performance. For instance, Wang et al. designed and developed an abasic-site-containing triplex molecular beacon (tMB) for sensitive recognition of melamine by integrating tMBs and fluorescent silver nanoclusters. ${ }^{18}$ Tang et al. established a sensitive "turn-on" fluorescent sensor for melamine based on FRET effect between polydopamine-glutathione nanoparticles and $\mathrm{Ag}$ nanoparticles. ${ }^{22}$ However, the nanomaterial based methods are usually complicated and costly due to the time-consuming 
synthesis procedure and the complex modification process. Therefore, it is necessary to explore cost effective, facile and reliable sensing strategy for melamine detection using generic laboratory equipment.

Alternatively, chemistry reaction based biological sensing system has gained growing popularity on account of the controllability and flexibility for manipulating the detection performance with high selectivity and speediness. ${ }^{30}$ Three typical chemical reactions including "click chemistry" reaction, Michael reaction and Fenton reaction are usually applied for building excellent sensing platform especially for the effective signal translation and amplification. ${ }^{31-34}$ Among them, Fenton reaction as an inorganic reaction, has attracted significant interest due to its unique characteristic of simplicity, rapidness and convenience. ${ }^{33,35-37}$ Among various Fenton reaction based methods for bioanalysis, colorimetric assay that only utilized the oxidation of the hydroxyl radicals $(\cdot \mathrm{OH})$ produced by the Fenton reaction, has attracted significant interest due to its rapidness, obvious colour change, no need to use expensive analytical instruments and simple readout with the naked eye. The reaction between $3,3^{\prime}, 5,5^{\prime}$-tetramethylbenzidine (TMB) and hydrogen peroxide $\left(\mathrm{H}_{2} \mathrm{O}_{2}\right)$ was one of the most widely used colorimetric reactions for the detection of various targets including glucose ${ }^{38-40}$ histidine and cysteine,${ }^{41}$ cholesterol, ${ }^{42}$ $\mathrm{Cu}^{2+},{ }^{33,43} \mathrm{UA},{ }^{44,45}$ glyphosate ${ }^{46}$ and cancer cells. ${ }^{47}$ The catalysts of these TMB- $\mathrm{H}_{2} \mathrm{O}_{2}$ based colorimetric assays can be classified into four kinds, including horseradish peroxidase (HRP), HRPmimic DNAzyme, nanomaterial and metal ions. Compared with the other three catalysts, metal ions such as $\mathrm{Cu}^{2+}$ catalytic $\mathrm{H}_{2} \mathrm{O}_{2}$-TMB system not only exhibits high sensitivity, but also possesses some unique advantages including convenience, high stability, low cost and $\mathrm{Cu}^{2+}$ can be used directly in the TMB$\mathrm{H}_{2} \mathrm{O}_{2}$ reaction. ${ }^{45,46}$

Considering the fact that melamine can quickly interact with $\mathrm{H}_{2} \mathrm{O}_{2}$ producing the addition compound of $\mathrm{C}_{3} \mathrm{H}_{6} \mathrm{~N}_{6} \cdot \mathrm{H}_{2} \mathrm{O}_{2}$ which is stable even under $100{ }^{\circ} \mathrm{C}$ according to the thermal analysis results, ${ }^{48}$ the determination of melamine based on the consumption of $\mathrm{H}_{2} \mathrm{O}_{2}$ in $\mathrm{H}_{2} \mathrm{O}_{2}$ related reaction have been reported. ${ }^{28,49}$ Inspired by the above reports, herein, we explored a new simple $\mathrm{Cu}^{2+}-\mathrm{H}_{2} \mathrm{O}_{2}$-TMB system based colorimetric method for the detection of melamine without any modification or preparation of nanomaterials. In this method, $\mathrm{Cu}^{2+}$ can catalyse the oxidation of TMB to oxidized TMB (oxTMB) with the colour changing from colourless to blue in the presence of $\mathrm{H}_{2} \mathrm{O}_{2}$ due to the generation of $\cdot \mathrm{OH}$ by the $\mathrm{Cu}^{2+}$-based Fenton reaction. However, the presence of melamine quickly interacts with $\mathrm{H}_{2} \mathrm{O}_{2}$ to form stable $\mathrm{C}_{3} \mathrm{H}_{6} \mathrm{~N}_{6} \cdot \mathrm{H}_{2} \mathrm{O}_{2}$ complex, resulting the consumption of $\mathrm{H}_{2} \mathrm{O}_{2}$ and thus strongly inhibits the oxidation of TMB. The degree of colour change or absorbance decrease can be used for the detection of melamine by either the visually observed directly or the spectrometer. Taking advantages of the stable addition compound of $\mathrm{C}_{3} \mathrm{H}_{6} \mathrm{~N}_{6} \cdot \mathrm{H}_{2} \mathrm{O}_{2}$ for consumption of $\mathrm{H}_{2} \mathrm{O}_{2}$ and the effective $\mathrm{Cu}^{2+}-\mathrm{H}_{2} \mathrm{O}_{2}$-TMB catalyst system, the proposed method does not need any modification of probe or complicated operations, making it simple but reliable, and can be successfully applied for the detection of melamine in dairy products.

\section{Experimental section}

\subsection{Reagents and apparatus}

Melamine and 3,3',5,5'-tetramethylbenzidine (TMB), glucose (Glu), sucrose (Suc), galactose (Gal), glycine (Gly), aspartic acid (Asp), alanine (Ala), arginine (Arg) and leucine (Leu) were purchased from Aladdin Reagent Co., Ltd. (Shanghai, China). Hydrogen peroxide $\left(\mathrm{H}_{2} \mathrm{O}_{2}, 30 \mathrm{wt} \%\right)$, and the metal salts include $\mathrm{NaCl}, \mathrm{KCl}, \mathrm{CaCl}_{2}$ and $\mathrm{Zn}(\mathrm{Ac})_{2}$ were obtained from Sinopharm Chemical Reagent Co. Ltd. The milk and infant formula powder were obtained from local supermarkets. A $50 \mathrm{mM}$ HAc-NaAc buffer ( $\mathrm{pH}$ 4.0) was used in the experiments. Ultrapure water with a resistivity $>18 \mathrm{M} \Omega \mathrm{cm}$ produced using a Millipore system was utilized in the preparation of all aqueous solutions. The ultraviolet-visible (UV-vis) absorption spectra were recorded using a Cary 300 Bio UV-vis spectrophotometer.

\subsection{Detection of melamine}

Typically, $50 \mu \mathrm{L}$ of melamine with different concentrations, 20 $\mu \mathrm{L}$ of $5 \mathrm{mM} \mathrm{H}_{2} \mathrm{O}_{2}$, and $20 \mu \mathrm{L}$ of $20 \mathrm{mM} \mathrm{Cu}^{2+}$ were first added into a $1.5 \mathrm{~mL}$ centrifuge tube and mixed together. Then, $860 \mu \mathrm{L}$ of HAc-NaAc buffer and $50 \mu \mathrm{L}$ of $10 \mathrm{mM}$ TMB were added in the above reaction solution to give a final volume of $1 \mathrm{~mL}$. The mixed solution was incubated in a $40{ }^{\circ} \mathrm{C}$ water bath for $60 \mathrm{~min}$. Finally, the UV-vis absorption spectrum of the reacted mixture was recorded over the wavelength ranging from $500 \mathrm{~nm}$ to $800 \mathrm{~nm}$.

\subsection{Detection of melamine in dairy products}

The milk and infant formula powder samples were prepared according to a previous report with a minor modification. ${ }^{28}$ In this work, $2.0 \mathrm{~mL}$ liquid milk or $20 \mathrm{mg}$ infant formula powder was added to the solution containing $7.0 \mathrm{~mL}$ of water and $1.0 \mathrm{~mL}$ of acetonitrile. $1.0 \mathrm{~mL}$ trichloroacetic acid $(2 \mathrm{M})$ was then added into the above solution. Then, the mixture was treated under ultrasonic for $20 \mathrm{~min}$ and further shaken for $15 \mathrm{~min}$. After that, the mixture was centrifuged at $10000 \mathrm{rpm}$ for $10 \mathrm{~min}$ to separate the deposit. The supernatant was adjusted to $\mathrm{pH} 7.0$ with $\mathrm{NaOH}$ solution $(1 \mathrm{M})$ and used for the following detection as that in HAc-NaAc buffer. The liquid milk and infant formula powder spiked melamine samples for the recovery experiments were treated as the same procedures aforementioned.

\section{Results and discussion}

\subsection{Mechanism of colorimetric assay}

A simple and reliable $\mathrm{Cu}^{2+}-\mathrm{H}_{2} \mathrm{O}_{2}$-TMB system based colorimetric method was constructed for the detection of melamine without any modification or preparation of nanomaterials, which is presented schematically in Scheme 1 . Two reactions were involved for the determination of melamine by this method. As reported previously, $\mathrm{Cu}^{2+}$ can work as Fenton-like agent and catalyse the oxidation of peroxidase substrate TMB in the presence of $\mathrm{H}_{2} \mathrm{O}_{2}$, leading to a blue coloured product oxTMB (Reaction 1). ${ }^{45,46}$ There are three amino groups in melamine molecule which endows it excellent reducibility. 


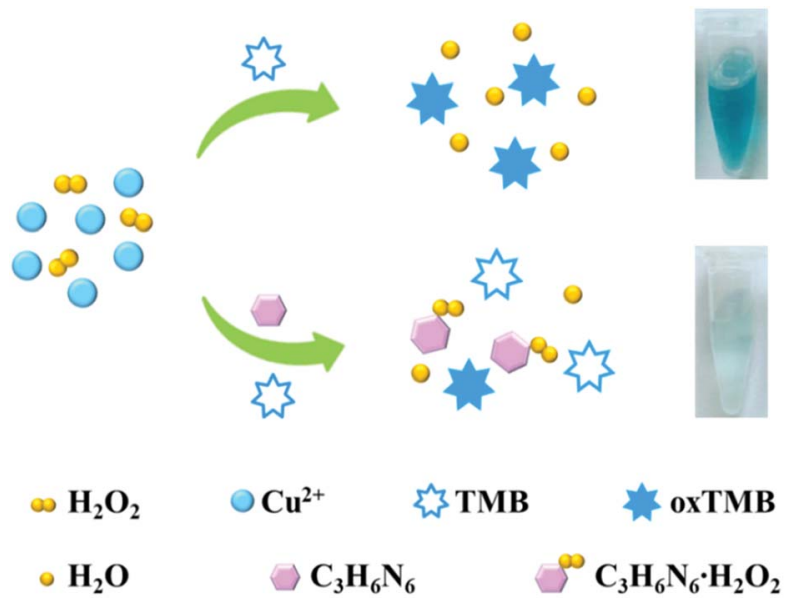

Scheme 1 Schematic illustration of the colorimetric sensing system for melamine detection.

Therefore, when added melamine into the system, melamine can quickly react with $\mathrm{H}_{2} \mathrm{O}_{2}$ which possesses good oxidation property to generate a stable addition compound $\mathrm{C}_{3} \mathrm{H}_{6} \mathrm{~N}_{6} \cdot \mathrm{H}_{2} \mathrm{O}_{2}$ (Reaction 2). ${ }^{28,49}$

$$
\begin{gathered}
\mathrm{H}_{2} \mathrm{O}_{2}+\mathrm{TMB} \stackrel{\mathrm{Cu}^{2+}}{\longrightarrow} \text { oxTMB }+\mathrm{H}_{2} \mathrm{O} \\
\mathrm{C}_{3} \mathrm{H}_{6} \mathrm{~N}_{6}+\mathrm{H}_{2} \mathrm{O}_{2} \rightarrow \mathrm{C}_{3} \mathrm{H}_{6} \mathrm{~N}_{6} \cdot \mathrm{H}_{2} \mathrm{O}_{2}
\end{gathered}
$$

On the basis of the above two reactions, the presence of melamine leads to the quickly consumption of $\mathrm{H}_{2} \mathrm{O}_{2}$ and thus inhibits the $\mathrm{Cu}^{2+}$-based Fenton-like reaction, resulting in a low efficiency of the $\mathrm{Cu}^{2+}-\mathrm{H}_{2} \mathrm{O}_{2}$-TMB reaction. Consequently, the solution colour changed from blue to colourless with a remarkable decrease of peak absorbance. The degree of colour change or absorbance increase was directly related to the amount of melamine. Compared with the traditional sensing system for melamine, the $\mathrm{Cu}^{2+}-\mathrm{H}_{2} \mathrm{O}_{2}$-TMB system based colorimetric method is relatively easy to implement and inexpensive, since it offers a convenient "mix-and-detect" protocol for homogeneous detection and does not require complicated synthesis, modification, strict storage conditions, and expensive equipment.

In order to verify the colorimetric sensing mechanism, the catalytic oxidation TMB under different conditions was investigated. As shown in Fig. 1, the aqueous solution of TMB remains colourless and exhibits negligible absorbance at $652 \mathrm{~nm}$ (curve a), and no obvious change of absorption spectra is observed after the addition of $\mathrm{Cu}^{2+}$ to TMB solution (curve b). In contrast, the introduction of $\mathrm{H}_{2} \mathrm{O}_{2}$ and $\mathrm{Cu}^{2+}$ essentially triggers the oxidative reaction of TMB, during which the original colourless gradually turns to blue in colour and exhibits a remarkable absorption peaks at $652 \mathrm{~nm}$ (curve c). As expected, when melamine is added into the $\mathrm{Cu}^{2+}-\mathrm{H}_{2} \mathrm{O}_{2}$-TMB system, the blue colour fades and the absorbance at $652 \mathrm{~nm}$ decreases obviously (curve d). The results confirmed that the reaction activity of $\mathrm{Cu}^{2+}-\mathrm{H}_{2} \mathrm{O}_{2}$-TMB system is indeed inhibited by melamine owing to the consumption of $\mathrm{H}_{2} \mathrm{O}_{2}$ by formation of $\mathrm{C}_{3} \mathrm{H}_{6} \mathrm{~N}_{6} \cdot \mathrm{H}_{2} \mathrm{O}_{2}$ complex.

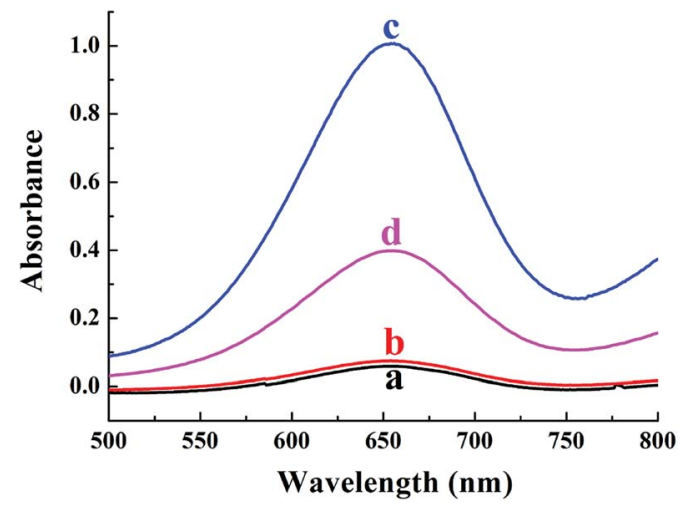

Fig. 1 UV-vis absorption spectra of the colorimetric sensing system at different conditions: (a) TMB, (b) TMB $+\mathrm{Cu}^{2+}$, (c) $\mathrm{TMB}+\mathrm{Cu}^{2+}+\mathrm{H}_{2} \mathrm{O}_{2}$, (d) $\mathrm{TMB}+\mathrm{Cu}^{2+}+\mathrm{H}_{2} \mathrm{O}_{2}+$ melamine. The concentrations of TMB, $\mathrm{Cu}^{2+}$, $\mathrm{H}_{2} \mathrm{O}_{2}$ and melamine are $0.5 \mathrm{mM}, 400 \mu \mathrm{M}, 100 \mu \mathrm{M}$ and $100 \mu \mathrm{M}$, respectively.

These results substantially indicate that the proposed method is suitable for the sensitive detection of melamine.

\subsection{Optimization of assay conditions}

To explore a highly sensitive response to melamine in UV-vis detection, several important reaction conditions were optimized before the standard melamine assay, including the concentrations of $\mathrm{TMB}, \mathrm{Cu}^{2+}$ and $\mathrm{H}_{2} \mathrm{O}_{2}$, the $\mathrm{pH}$ of reaction buffer, the incubation time and temperature. The absorbance difference $\Delta A_{652}=A_{0}-A$ was employed to evaluate the optimization of the variables, where $A_{0}$ and $A$ represented the absorbance at $652 \mathrm{~nm}$ in the absence and presence of $100 \mu \mathrm{M}$ melamine, respectively. As shown in Fig. 2A, the absorbance is enhanced significantly as TMB concentration is increased, and then reached a maximum value until $0.5 \mathrm{mM}$. Hence, $0.5 \mathrm{mM}$ was chosen as the optimal TMB concentration in the following experiments. Considering the fact that the oxidative of TMB requires the coexistence of the metal ion mimic peroxidase $\mathrm{Cu}^{2+}$
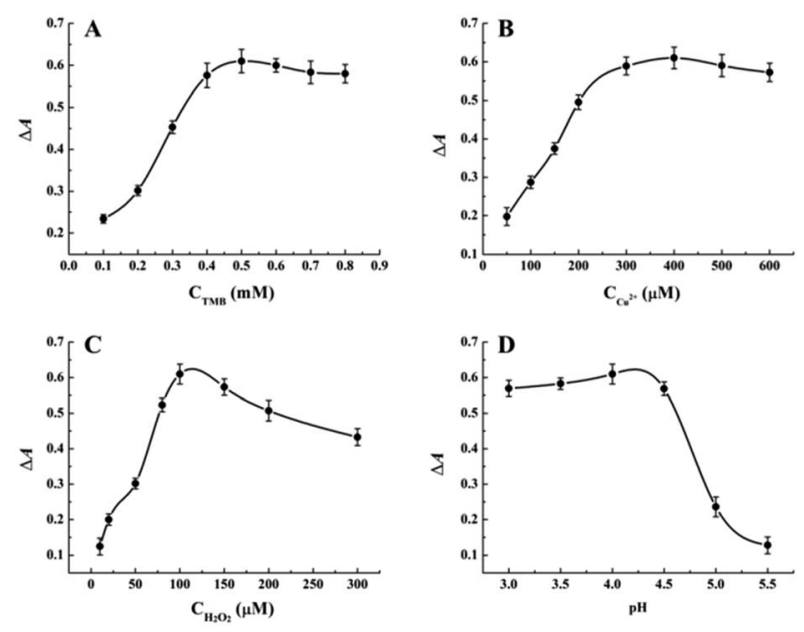

Fig. 2 Optimization of the detection conditions for melamine. The absorbance changes at $652 \mathrm{~nm}$ versus the concentrations of (A) TMB, (B) $\mathrm{Cu}^{2+}$, (C) $\mathrm{H}_{2} \mathrm{O}_{2}$ and the (D) $\mathrm{pH}$ values. Error bars were estimated from three replicate measurements. 
and $\mathrm{H}_{2} \mathrm{O}_{2}$, the concentrations of them were optimized then. Fig. 2B and $\mathrm{C}$ show the absorbance changes of $\mathrm{Cu}^{2+}-\mathrm{H}_{2} \mathrm{O}_{2}-\mathrm{TMB}$ sensing system upon the treatment with different concentrations of $\mathrm{Cu}^{2+}$ and $\mathrm{H}_{2} \mathrm{O}_{2}$ while fixing the concentration of melamine at $100 \mu \mathrm{M}$, respectively. The results indicated that the optimum concentrations of $\mathrm{Cu}^{2+}$ and $\mathrm{H}_{2} \mathrm{O}_{2}$ are $400 \mu \mathrm{M}$ and 100 $\mu \mathrm{M}$, respectively. It is well-known that the oxidative reaction of TMB is strongly dependent on the $\mathrm{pH}$ of reaction buffer. Therefore, the effect of $\mathrm{pH}$ on catalytic activity of $\mathrm{Cu}^{2+}-\mathrm{H}_{2} \mathrm{O}_{2}$ TMB sensing system was studied in the range of 3.0-6.0. As shown in Fig. 2D, the value of $\Delta A_{652}$ increases gradually and reaches a maximum at $\mathrm{pH} 4.0$ and then decreases with further increasing $\mathrm{pH}$ value. Thus, the HAc-NaAc buffer with $\mathrm{pH} 4.0$ was chosen in the following experiments. Moreover, the investigation results of incubation time indicate that the maximum value of $\Delta A_{652}$ can be obtained when reaction time is $60 \mathrm{~min}$ (Fig. S1 $\dagger$ ). Subsequently, the incubation temperature in the range of $25-50{ }^{\circ} \mathrm{C}$ was investigated and shown in Fig. S2. $\dagger$ It can be seen that the temperature being neither too high nor too low is suitable for this enzyme mimetic reaction. Therefore, $40{ }^{\circ} \mathrm{C}$ was selected as the optimal incubation temperature.

\subsection{Analytical performance for the detection of melamine}

Under the optimal conditions, the quantitative analysis capacity of the developed colorimetric sensing system for melamine was investigated. As shown in Fig. 3A, it is clearly seen that with the increase of melamine concentrations ranging from 0 to $500 \mu \mathrm{M}$, the absorbance at $652 \mathrm{~nm}$ of the $\mathrm{Cu}^{2+}-\mathrm{H}_{2} \mathrm{O}_{2}$-TMB sensing system decreases gradually while $\Delta A_{652}$ increases systematically, indicating that the inhibition of the oxidation of TMB by $\mathrm{H}_{2} \mathrm{O}_{2}$ is dependent on the concentration of melamine. Fig. 3B exhibits that a good linear correlation is obtained between the absorbance at $652 \mathrm{~nm}$ and the melamine concentration ranging from 1 to $100 \mu \mathrm{M}$, with the regression equation of $\Delta A_{652}=0.01403+$ $0.00621 C_{\text {Melamine }}(\mu \mathrm{M})$, and the correlation coefficient of $R^{2}=$ 0.9905. The detection limit of the melamine assay is estimated
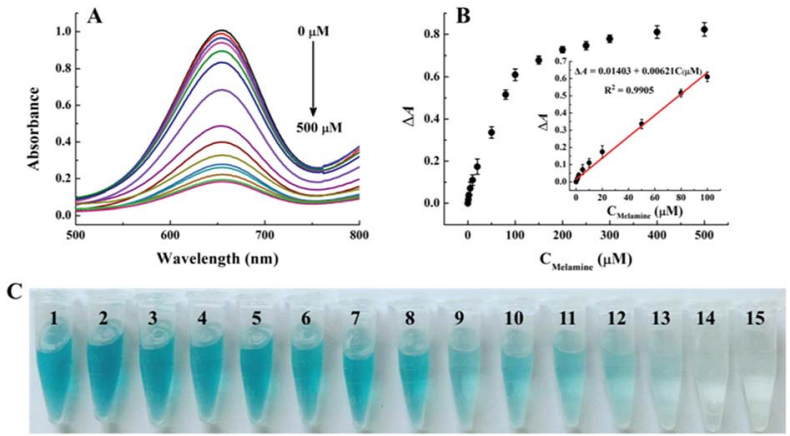

Fig. 3 (A) The UV-vis absorption spectra of the colorimetric sensing system in the presence of different concentrations of melamine. (B) The relationship between melamine concentration and absorbance changes at $652 \mathrm{~nm}$. Inset: the linear region at low melamine concentrations. (C) Typical photographs for different concentrations of melamine under the optimum conditions, from 1 to 15 are $0,1,2,5$, $10,20,50,80,100,150,200,250,300,400$ and $500 \mu \mathrm{M}$, respectively. Error bars were estimated from three replicate measurements. to be $0.5 \mu \mathrm{M}$ based on $3 \sigma /$ slope, which is comparable to or lower than those of previously reported traditional instrumental assays such as HPLC and LC/MS., ${ }^{\mathbf{8 1 0}}$ In addition, we compared the analytical performance of the proposed sensing system with other recently reported methods including electrochemical, fluorescent and colorimetric assays. As shown in Table $\mathrm{S} 1, \uparrow$ the sensitivity of the $\mathrm{Cu}^{2+}-\mathrm{H}_{2} \mathrm{O}_{2}$-TMB sensing system is superior or comparable to most reported strategies. More importantly, our strategy is label-free and does not require complicated synthesis or strict storage conditions which endows it many advantages including low cost, simple operation and thus more practical. At the same time, the colour of the $\mathrm{Cu}^{2+}-\mathrm{H}_{2} \mathrm{O}_{2}$-TMB system gradually turns initially from blue to colourless and the obvious colour variation is depicted in Fig. 3C. The colour change can be distinguished by the naked eye with the concentration of melamine around $20 \mu \mathrm{M}$, indicating the simplicity and convenience in the detection of melamine compared with those methods that require expensive instruments.

As the nutrient contents of dairy products are complicated, it is important to evaluate the specificity of the proposed colorimetric method for melamine detection, we investigated the absorbance changes as induced by some possible interference including some metal ions, amino acids, and sugars. As shown in Fig. 4, melamine exhibits the highest value of $\Delta A_{652}$ and the values of $\Delta A_{652}$ of other interferences are almost negligible even if others concentration is 100 times higher than melamine. The good selectivity may be attributed to the specific additional reaction of melamine with $\mathrm{H}_{2} \mathrm{O}_{2}$. These results proved the good sensitivity and selectivity of this method and the possibility for detecting melamine in dairy products.

\subsection{Detection of melamine in dairy product samples}

In order to evaluate the feasibility of the colorimetric sensing system in real samples, the recovery experiments of melamine were investigated by spiking melamine with different concentrations into liquid milk and infant formula powder according

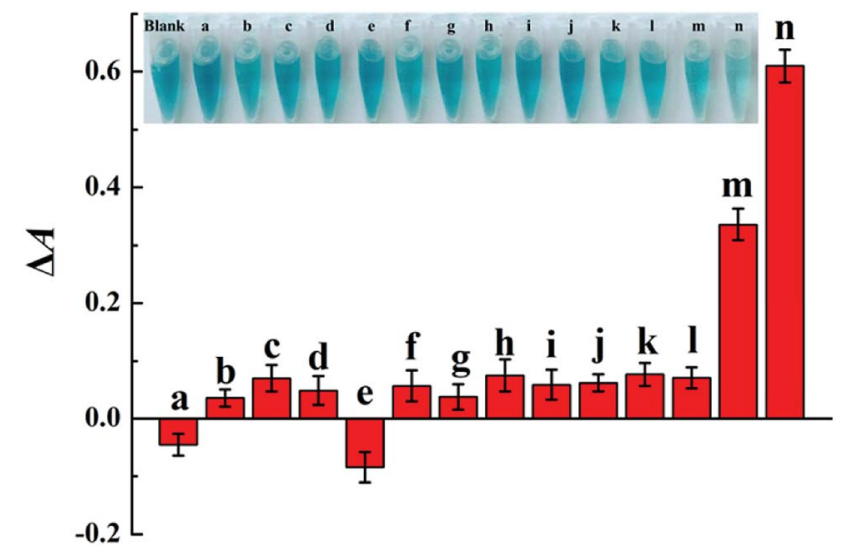

Fig. 4 Selectivity of the colorimetric sensing system for melamine detection. From a to $\mathrm{n}$ are $\mathrm{Na}^{+}, \mathrm{K}^{+}, \mathrm{Ca}^{2+}, \mathrm{Zn}^{2+}, \mathrm{Glu}, \mathrm{Suc}, \mathrm{Gal}$, Asp, Gly, Ala, Arg, Leu, $50 \mu \mathrm{M}$ melamine and $100 \mu \mathrm{M}$ melamine, respectively. The concentration of the interference substances are all $100 \mu \mathrm{M}$, respectively. The inset is the corresponding photographs. Error bars were estimated from three replicate measurements. 
to the same detection procedure as in HAc-NaAc buffer. It is worth noting that ascorbic acid, namely vitamin $\mathrm{C}$ (Vit C), as an essential nutrient added into dairy products may be a potential interfering substance due to its antioxidant property. Therefore, the controlling experiment was first conducted in dairy product samples to confirm that the necessity of melamine to induce the absorbance change while the presence of Vit $\mathrm{C}$ has no obvious interference. As shown in Fig. 5, compared to the absorbance change of the sensing system upon the addition of melamine $(20 \mu \mathrm{M})$, weaker absorbance changes are observed by Vit $\mathrm{C}$ even though at the concentration of 5 times as that of melamine. The result implied the necessity of melamine for the consumption of $\mathrm{H}_{2} \mathrm{O}_{2}$ and thus inducing absorbance change and the weak interference of Vit $\mathrm{C}$ added as an essential nutrient in both liquid milk and infant formula powder. The weak interference of Vit $\mathrm{C}$ might be owing to the following two accounts: the milk proteins in dairy products might induce "disappearance" of Vit $\mathrm{C}$ and slowed down the auto-oxidation of Vit $\mathrm{C}$ significantly; the excellent reducibility of the three amino groups endows melamine with prior redox of melamine- $\mathrm{H}_{2} \mathrm{O}_{2}$ in contrast to Vit C. ${ }^{49}$

Then, the recovery experiments were carried out by spiking different concentrations of melamine in each sample to evaluate the accuracy of the colorimetric sensing system as no melamine was found in both liquid milk and infant formula powder. As shown in Table 1, the recoveries for melamine are

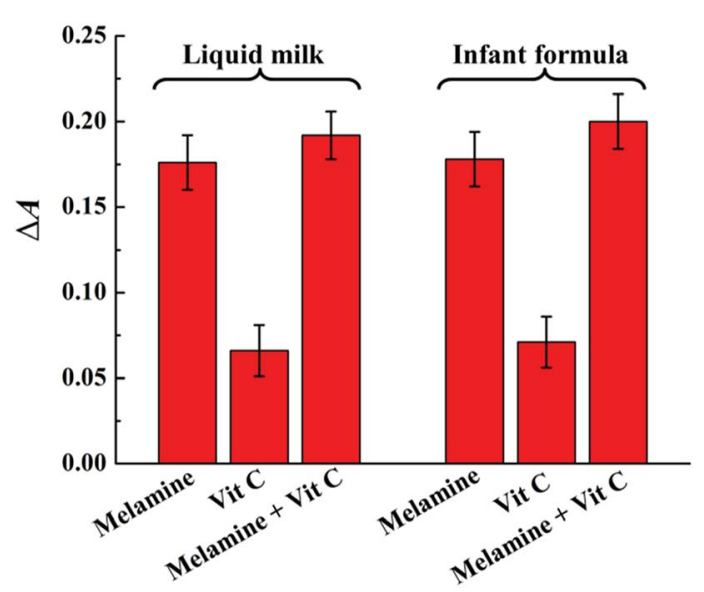

Fig. 5 The responses of the colorimetric sensing system for melamine $(20 \mu \mathrm{M})$ and Vit $C(100 \mu \mathrm{M})$ detection in liquid milk and infant formula powder samples. Error bars were estimated from three replicate measurements.

Table 1 Detection of melamine spiked in dairy product samples

\begin{tabular}{lcccl}
\hline Sample & Added $(\mu \mathrm{M})$ & Found $(\mu \mathrm{M})$ & Recovery $(\%)$ & $\begin{array}{l}\text { RSD } \\
(n=3, \%)\end{array}$ \\
\hline Liquid milk & 5.0 & 4.8 & 96.0 & 4.5 \\
& 20.0 & 20.3 & 101.5 & 3.9 \\
Infant formula & 50.0 & 50.1 & 100.2 & 3.8 \\
powder & 5.0 & 5.2 & 104.0 & 4.2 \\
& 20.0 & 20.9 & 104.5 & 4.7 \\
& 50.0 & 51.9 & 103.8 & 3.2
\end{tabular}

ranging from $96.0 \%$ to $104.5 \%$, and the relative standard deviations (RSDs) are all below 4.7\%, demonstrating no severe interference in the tested dairy product samples. In addition, under the optimal conditions, a weak decrease in absorbance can be observed for all the samples, which may be due to a slight interference in the oxidization of TMB reaction by some possible reducing components in the milk samples. Fortunately, the calibration curve of the assay between $\Delta A_{652}$ and the spiked melamine concentration for the liquid milk samples was similar to that in the buffer system (Fig. S3A $\dagger$ ), and the colour change can also be distinguished by the naked eye with the concentration of melamine around $20 \mu \mathrm{M}$ as similar to that in buffer system (Fig. S3B $\dagger$ ). Therefore, the encouraging results demonstrate the great promise of this method for monitoring melamine in real samples.

\section{Conclusions}

In summary, we demonstrated a convenient label free colorimetric $\mathrm{Cu}^{2+}-\mathrm{H}_{2} \mathrm{O}_{2}$-TMB sensing system for sensitive detection of melamine based on the consumption of $\mathrm{H}_{2} \mathrm{O}_{2}$ by melamine induced inhibition effect of $\mathrm{Cu}^{2+}-\mathrm{H}_{2} \mathrm{O}_{2}$-TMB reaction. $\mathrm{Cu}^{2+}$ can catalyse the oxidation of TMB to oxTMB in the presence of $\mathrm{H}_{2} \mathrm{O}_{2}$ with a blue colour change of the solution. However, the quickly and stable addition reaction between melamine and $\mathrm{H}_{2} \mathrm{O}_{2}$ disturbed the $\mathrm{Cu}^{2+}-\mathrm{H}_{2} \mathrm{O}_{2}$-TMB reaction, resulting in a fading change of the reaction system which can be distinguished by naked eyes for about $20 \mu \mathrm{M}$ melamine. Since no complicated synthesis and modification of signal probes or tedious procedures involved, the developed visual assay is cost-effective and convenient compared with the traditional melamine assays. Using the sensitive and selective sensing system, the liquid milk and infant formula powder samples contained melamine could also be detected successfully. Therefore, the present sensing system holds the potential for reliable screening melamine in real dairy products, ensuring both public health and food security.

\section{Conflicts of interest}

There are no conflicts of interest to declare.

\section{Acknowledgements}

Xue Han and Zhixin Qin contributed equally to this work. This work was supported by the National Natural Science Foundation of China (21775089), the Natural Science Foundation Projects of Shandong Province (ZR2017QB008, ZR2017JL010), and the National Undergraduate Innovation and Entrepreneurship Training Program (201710446039).

\section{Notes and references}

1 T. L. Fodey, C. S. Thompson, I. M. Traynor, S. A. Haughey, K. D. Glenn and S. R. H. Crooks, Anal. Chem., 2011, 83, 5012-5016. 
2 K. L. Ai, Y. L. Liu and L. H. Lu, J. Am. Chem. Soc., 2009, 131, 9496-9497.

3 C. Fu, C. Liu, Y. Li, Y. Guo, F. Luo, P. Wang, L. Guo, B. Qiu and Z. Lin, Anal. Chem., 2016, 88, 10176-10182.

4 R. Reimschuessel and B. Puschner, J. Med. Toxicol., 2010, 6, 468-469.

5 L. Zhu, G. Gamez, H. Chen, K. Chingin and R. Zenobi, Chem. Commun., 2009, 5, 559-561.

6 http://www.fda.gov/NewsEvents/PublicHealthFocus/ ucm179005.htm, 2009.

7 F. Sun, W. Ma, L. Xu, Y. Zhu, L. Liu, C. Peng, L. Wang, H. Kuang and C. Xu, Trends Anal. Chem., 2010, 29, 12391249.

8 Y. Zhang, S. Lin, P. Jiang, X. Zhu, J. Ling, W. Zhang and X. Dong, J. Chromatogr. A, 2014, 1337, 17-21.

9 H. Miao, S. Fan, Y. N. Wu, L. Zhang, P. P. Zhou, J. G. Li, H. J. Chen, Y. F. Zhao and J. G. Li, Biomed. Environ. Sci., 2009, 22, 87-94.

10 M. S. Filigenzi, B. Puschner, L. S. Aston and R. H. Poppenga, J. Agric. Food Chem., 2008, 56, 7593-7599.

11 N. Yan, L. Zhou, Z. F. Zhu and X. Chen, J. Agric. Food Chem., 2009, 57, 807-811.

12 P. Ma, F. Liang, Y. Sun, Y. Jin, Y. Chen, X. Wang, H. Zhang, D. Gao and D. Song, Microchim. Acta, 2013, 180, 1173-1180.

13 C. Han, Y. Li, Q. Jia, L. H. Bradley, Y. Gan, Y. Yao, L. Qu, H. Li and Y. Zhao, Microchim. Acta, 2017, 184, 2909-2917.

14 H. Lei, Y. Shen, L. Song, J. Yang, O. P. Chevallier, S. A. Haughey, H. Wang, Y. Sun and C. T. Elliott, Anal. Chim. Acta, 2010, 665, 84-90.

15 X. Liu, M. Song and F. Li, Sci. Rep., 2017, 7, 4490.

16 N. Chen, Y. Cheng, C. Li, C. Zhang, K. Zhao and Y. Xian, Microchim. Acta, 2015, 182, 1967-1975.

17 H. W. Zhu, W. X. Dai, X. D. Yu, J. J. Xu and H. Y. Chen, Talanta, 2015, 144, 642-647.

18 Y. Wang, Q. Sun, L. Zhu, J. Zhang, F. Wang, L. Lu, H. Yu, Z. Xu and W. Zhang, Chem. Commun., 2015, 51, 7958-7961.

19 X. Liu, N. Xu, P. Gai and F. Li, Talanta, 2018, 185, 352-358.

20 Q. Du, F. Qu, B. Mao, S. Zhu and J. You, New J. Chem., 2016, 40, 8459-8464.

21 F. Qu, X. Xu and J. You, New J. Chem., 2017, 41, 9438-9443.

22 L. Tang, S. Mo, S. G. Liu, Y. Ling, X. F. Zhang, N. B. Li and H. Q. Luo, J. Agric. Food Chem., 2018, 66, 2174-2179.

23 L. Zhang and L. Chen, Microchim. Acta, 2018, 185, 135.

24 N. Ding, N. Yan, C. Ren and X. Chen, Anal. Chem., 2010, 82, 5897-5899.

25 H. Hu, J. Zhang, Y. Ding, X. Zhang, K. Xu, X. Hou and P. Wu, Anal. Chem., 2017, 89, 5101-5106.

26 W. F. Wang, Y. Qiang, X. H. Meng, J. L. Yang and Y. P. Shi, Sens. Actuators, B, 2018, 260, 808-815.
27 P. J. Ni, H. C. Dai, Y. L. Wang, Y. J. Sun, Y. Shi, J. T. Hu and Z. Li, Biosens. Bioelectron., 2014, 60, 286-291.

28 J. Song, F. Wu, Y. Wan and L. H. Ma, Microchim. Acta, 2014, 181, 1267-1274.

29 G. Wang, Y. Zhu, X. He, L. Chen, L. Wang and X. Zhang, Microchim. Acta, 2014, 181, 411-418.

30 H. Chen, Q. Lu, K. He, M. Liu, Y. Zhang and S. Yao, Sens. Actuators, B, 2018, 260, 908-917.

31 Y. Chen, Y. Xianyu, J. Wu, B. Yin and X. Jiang, Theranostics, 2016, 6, 969-985.

32 S. Krishnan, R. M. Miller, B. Tian, R. D. Mullins, M. P. Jacobson and J. Taunton, J. Am. Chem. Soc., 2014, 136, 12624-12630.

33 Z. Shan, M. Lu, L. Wang, B. MacDonald, J. MacInnis, M. Mkandawire, X. Zhang and K. D. Oakes, Chem. Commun., 2016, 52, 2087-2090.

34 Z. Mao, Z. Qing, T. Qing, F. Xu, L. Wen, X. He, D. He, H. Shi and K. Wang, Anal. Chem., 2015, 87, 7454-7460.

35 Y. B. Ruan, C. Li, J. Tang and J. Xie, Chem. Commun., 2010, 46, 9220-9222.

36 W. Cui, H. Qin, Y. Zhou and J. Du, Microchim. Acta, 2017, 184, 1103-1108.

37 L. Zhang, M. Li, Y. Qin, Z. Chu and S. Zhao, Analyst, 2014, 139, 6298-6303.

38 F. Qiao, L. Chen, X. Li, L. Li and S. Ai, Sens. Actuators, B, 2014, 193, 255-262.

39 T. Lin, L. Zhong, Z. Song, L. Guo, H. Wu, Q. Guo and G. Chen, Biosens. Bioelectron., 2014, 62, 302-307.

40 X. Tian, X. Wang, C. Dai, Y. Li, C. Yang, Z. Zhou and Y. Wang, Sens. Actuators, B, 2017, 245, 221-229.

41 C. Wu, D. Fan, C. Zhou, Y. Liu and E. Wang, Anal. Chem., 2016, 88, 2899-2903.

42 N. R. Nirala, S. Abraham, V. Kumar, A. Bansal, A. Srivastava and P. S. Saxena, Sens. Actuators, B, 2015, 218, 42-50.

43 W. Li, X. Zhao, J. Zhang and Y. Fu, Biosens. Bioelectron., 2014, 60, 252-258.

44 Q. Lu, J. Deng, Y. Hou, H. Wang, H. Li and Y. Zhang, Chem. Commun., 2015, 51, 12251-12253.

45 H. F. Lu, J. Y. Li, M. M. Zhang, D. Wu and Q. L. Zhang, Sens. Actuators, B, 2017, 244, 77-83.

46 Y. Q. Chang, Z. Zhang, J. H. Hao, W. S. Yang and J. L. Tang, Sens. Actuators, B, 2016, 228, 410-415.

47 W. Zhou, W. Liang, X. Li, Y. Chai, R. Yuan and Y. Xiang, Nanoscale, 2015, 7, 9055-9061.

48 J. Wielicka, A. Ptasiewicz-Malinowska, T. Jędrych, M. Minda, B. Wiejak, T. Pajer, W. Ratajczak, M. Michalska and W. Capała, Pol. J. Chem. Technol., 2003, 5, 19-21.

49 W. L. Li, F. Z. Kong, Q. Zhang, W. W. Liu, H. Kong, X. P. Liu, M. I. Khan, A. Wahid, S. Saud, H. Xiao, C. X. Cao and L. Y. Fan, Anal. Chem., 2018, 90, 6710-6717. 